\title{
Uma leitura sobre Paulo Freire em três eixos articulados: o homem, a educação e uma janela para o mundo
}

Paulo Gomes Lima*

http://dx.doi.org/10.1590/0103-7307201407504

\section{Resumo}

Em três eixos articulados, o presente artigo discute a contribuição de Paulo Freire e a atualidade de seu pensamento para a educação, a busca pela superação da consciência ingênua para uma consciência crítico-reflexiva e, consequentemente, a leitura e a * Universidade Federal de São Carlos, Sorocaba, SP. Brasil. paulolima@ufscar.br ação necessárias para a constituição de sujeitos que mobilizam a história e se mobilizam com ela. No primeiro eixo, "Paulo Freire o homem", opta-se por discutir a escolha da luta de Paulo Freire pelo despertamento dos oprimidos, tendo a educação como um dos instrumentos possíveis para a libertação. No segundo eixo, "Paulo Freire e a educação", são organizadas as principais teses de sua luta pela libertação e emancipação das classes menos favorecidas; e, finalmente, no terceiro eixo, "Paulo Freire - uma janela para o mundo", discute-se o anúncio de uma voz atual e necessária à denúncia de um jogo político que, negando o seu próprio discurso pela democratização e universalização, é conivente com uma escola dualista. Na perspectiva freireana, o texto conclui que a educação democrática não pode existir sem uma sociedade que acompanhe o mesmo adjetivo.

\section{Palavras-chave}

Paulo Freire, educação escolar, democracia. 


\title{
Reading Paulo Freire in three articulated axes: the man, the education, and $a$ window to the world
}

\begin{abstract}
This article discusses the contributions of Paulo Freire and the actuality of his thought for education, for overcoming naive consciousness, and for the action necessary to the constitution of subjects that act with and within history. In the first part, I discuss Paulo Freire's struggle for awakening the oppressed, taking education as one of the possible instruments for this mission. In the second part, I discuss the main theses of his work regarding the struggle for liberation and emancipation of disadvantaged classes, and finally, in the third part I discuss his criticism of the dual school. The article shows in the end that a democratic education cannot exist without a society that follows the same adjective
\end{abstract}

Keywords Paulo Freire, school education, democracy. 


\section{Introdução}

O pensamento de Paulo Freire é indissociável do principal objeto de sua preocupação em vida: a educação, pois, como homem, isto é, ser capaz de se autoproduzir e ressignificar sua existência a partir do outro, defendia que, embora a educação, sozinha, dissociada da vida social, não pudesse efetivamente transformar a realidade por conta dos jogos políticos e ideológicos de grupos hegemônicos, poderia ser uma janela para o mundo. Sua credibilidade na transformação social estava balizada pelo posicionamento sociopolítico dos educadores e dos brasileiros e brasileiras que descobrissem não somente uma janela, senão o mundo mesmo, inferindo as transformações necessárias ao exercício da cidadania negada historicamente.

Nesse contexto, como observa Lima (2013b), a educação assume a tarefa social de despertar no homem a consciência de si e do outro no mundo, contribuindo, de forma relevante, para o seu crescimento formativo e informativo, favorecendo o seu exercício ativo em todos os processos de sua história (e implicações advindas desses). Consequentemente, ela, cuja finalidade maior é a de elevar o homem à categoria de sujeito de sua própria história em construção, mediatizada pela compreensão, interpretação e crítica (essas sempre em processo) de sua realidade (envolvendo aqui toda a valoração do homem em sua totalidade: social, política, econômica, mas acima de tudo do homem como homem, propriamente dito), pode desfazer as tramas reducionistas dessa realidade histórica (que é sobretudo vivida), considerando o seu universo relacional, que possui essencialmente um caráter multidimensional. Essa promoção do homem como ser social adquire, como diz Freire (1980, p. 34), um caráter libertador, pois é um ato de conhecimento, uma apropriação legítima da realidade que considera "a vocação ontológica do homem - vocação de ser sujeito - e as condições em que ele vive: em tal lugar exato, em tal momento, em tal contexto". Nesse sentido, a educação não pode ser dissociada de um posicionamento político pelo professor, que, como sujeito recorrente, apropria-se dos fundamentos epistemológicos, articula-os de forma reflexiva à realidade, sem fragmentações, e cresce, de forma solidária e cidadã, junto com o sujeito cognoscente. Desse modo, o professor precisa assumir um papel interventivo especial, pois, como lembra Lima (2000), a prática reflexiva da realidade deve estar presente no dia a dia do educador como algo sempre novo, dinâmico, em construção e como processo multidimensional. 0 professor não apenas ensina a aprender, mas aprende a ensinar com seus alunos, com outros professores, com as situações vivenciadas, discutidas com perguntas e respostas ad- 
vindas de situações problematizadoras diversas, enfim, aprende com a socialização dos saberes e tal disposição deve ser o ponto central de sua prática cotidiana. Portanto, o professor, como agente facilitador do processo ensino-aprendizagem, pode viabilizar o despertamento dos sujeitos participantes desse processo, possibilitar, por meio de sua prática, a efetuação de inovadoras leituras de mundo e as contribuições significativas de vida e para a vida, se e tão somente se, estiver imbuído da responsabilização de fazer sua opção política em prol dos não reducionismos sociais e da aceitação de políticas compensatórias que destituem o direito e alienam homens e mulheres do conceito e da materialização da cidadania.

Essa preocupação com o ser do homem no mundo e o papel da educação, como instrumento de transformação de ambos, a partir de Paulo Freire e debatida no I Ciclo de Debates "Universidade e Educação Básica: a atualidade do pensamento de Paulo Freire", organizado por mim e desenvolvido por um grupo de professores da FAED e uma professora da FCH da Universidade Federal da Grande Dourados (UFGD), levou-me, inicialmente, a apresentar Paulo Freire - o homem, como um indivíduo que fez uma escolha em favor dos oprimidos, tendo a educação como instrumento; Paulo Freire e a educação, listando as principais teses orientadoras de sua luta pela libertação e emancipação das classes menos favorecidas; e Paulo Freire - uma janela para o mundo, como o anúncio de uma voz atual e necessária à denúncia de um jogo político que, negando o seu próprio discurso pela democratização e universalização, é conivente com uma escola dualista.

Paulo Freire é atual porque, mais do que nunca, como educadores, necessitamos revistar o status e o sentido de nossa ação interventiva na transformação social, considerando a situação histórica da humanidade, as estruturas sociais, a vida política, a vida econômica, as concepções de educação e escola, o perfil necessário de um educador libertador, dentre outros, pois a educação, quer em sentido amplo, quer em sentido específico, é um processo social. E, como tal, se dá num contexto de interações sociais, sendo uma das interfaces que possibilita entender a realidade social, formas de organização da sociedade e o modo como esses elementos influenciam a vida do indivíduo. Paulo Freire, inteirado da necessidade de uma ação consciente do papel da educação e da mobilização social, convida-nos a não somente refletir, mas a viver e a transformar os processos materiais da existência humana.

Este texto propõe-se a debater algumas de suas percepções aqui listadas, recor- 
rendo ao posicionamento de cada "leitor do mundo" quanto ao âmbito de equidade e justiça social que se quer para um mundo cuja teoria social precisa ser transformada.

\section{Paulo Freire: o homem}

Paulo Freire nasceu em 19 de setembro de 1921, em Recife. Graduou-se em Direito pela Universidade Federal de Pernambuco, mas não seguiu a profissão de advogado. Tendo optado pela carreira da educação, foi professor de português entre 1941 e 1947. A partir daí, ocupou alguns cargos sempre vinculados à área educacional: Diretor do Departamento de Educação e Cultura do SESI/PE (1946-1954), onde desenvolveu suas primeiras experiências com educação de trabalhadores, o que o conduziria mais tarde para o desenvolvimento de seu método, iniciado em 1961. Lecionou história e filosofia da educação na Universidade Federal de Pernambuco (1957-1963). No governo Goulart (1963), presidiu a Comissão Nacional de Cultura Popular e coordenou o Plano Nacional de Educação de Adultos. Em 1964, acusado de subversão, foi condenado a 15 anos de exílio pelo governo militar.

Pernambucano, era filho de um oficial da polícia militar, Joaquim Temístocles Freire, e de uma dona de casa, muito temente a Deus, Edeltrudes Neves Freire. Ao longo de suas obras, Paulo Freire registrou que, com seus pais, aprendera o diálogo, tema recorrente em toda a sua trajetória militante na educação. Aos 23 anos de idade (1944), o casamento com a professora Elza Maia Costa iria influenciá-lo significativamente como pensador e educador brasileiro, pois do comprometimento e da militância da esposa colecionara os testemunhos da realidade e a necessidade de uma escola transformadora.

Mesmo tendo se licenciado em Direito, percebeu imediatamente sua não compatibilidade com a área. Deveria haver para ele um trabalho que o encantasse e justificasse sua ação na história, mobilizada por um sentido maior de justiça e liberdade que a advocacia não the despertara. Assim, a educação escolar, que fora sempre um desafio aos seus olhos, aos poucos foi se tornando o principal objeto de seu cuidado. Estimulado pela esposa, foi trabalhar no Departamento de Educação do SESI (1946-1954), o que Ihe possibilitou a consolidação de sua escolha e seu propósito de vida profissional.

Entre os anos de 1961-1962, as condições de vida e educação das populações campesinas passaram a ser tema de sua indignação e busca de encaminhamentos para a construção de uma sociedade mais igualitária e alicerçada na justiça. Propunha que seria necessária uma leitura de mundo do sujeito cognoscente, de sua situação como protagonista, e isso só seria possível por meio de uma educação problematizadora. A 
partir desses pressupostos, criou o seu método de ensino, tendo significativa expressão no Movimento de Cultura Popular do Recife. 0 método em si não era o objetivo de sua razão de luta, mas uma forma de despertar, para a leitura da palavra, o grande contingente de analfabetos entre a população adulta. Vale dizer que, por essa época, a educação de adultos começou a ter uma relevância como nunca tinha tido anteriormente, ao ponto de, em 45 dias, os trabalhadores serem alfabetizados, refletindo a sua própria situação de classe.

Ao invés de denominar simplesmente de sala de aula, as classes de alfabetização eram chamadas, por ele, de Círculos de Cultura/Leitura, principalmente porque sua finalidade não era somente instrumental, mas sobretudo, uma forma de provocação da consciência das massas, isto é, nesses Círculos, os processos históricos de exclusão social - denunciados entre a leitura de mundo e a leitura da palavra - passavam a ser objeto de estudo, temário do conteúdo de seu método.

Essa proposta ganhou expressão, quando, em 1963, foi convidado pelo governo João Goulart para realizar a formação de coordenadores de Círculos de Leitura, entre junho de 1963 e março de 1964. Entretanto, com a eclosão da ditadura militar, em 1964, Paulo Freire foi preso por 70 dias e, imediatamente depois, exilado, por ser considerado um "subversivo internacional". A acusação era a de que seu método, comparado às perspectivas de Stálin, Hitler, Perón e Mussolini, provocava movimentos antipatriotas.

Estando no Chile, recebeu o reconhecimento de educador por excelência, cujas ideias e método, por conta de seu histórico, eram vistos com resistência pelos militantes governamentais, uma vez que o seu ideário se dirigia às massas oprimidas, despertando-lhes a percepção da necessidade de sua emancipação. Mas, ainda assim, obteve respaldo para o desenvolvimento de suas ideias e suas contribuições para a educação. Seu trabalho avançou também em outros países, via o Instituto de Ação Cultural (IDAC), que ajudou a fundar na Suiça no período de 1972-1974. Como exilado, esteve na Universidade de Harvard (EUA), na Tanzânia, em Guiné-Bissau, dentre outros e retornou ao Brasil, em 1979, por ocasião da anistia.

Recebeu inúmeras premiações, no Brasil e no exterior, depois do exílio, em reconhecimento pela sua contribuição na área educacional. Foi secretário municipal da educação na cidade de São Paulo (1989-1991) e desenvolveu docência e pesquisas na Pontifícia Universidade Católica de São Paulo (PUCSP) e na Universidade Estadual de Campinas/SP (Unicamp). Faleceu em 1997, deixando significativa produção literária, 
da qual se destacam: Pedagogia do oprimido (traduzido em 18 línguas), Conscientização, Educação como prática da liberdade, Pedagogia da esperança, Pedagogia da autonomia, Ação cultural para a liberdade, A importância do ato de ler, Educação e mudança, dentre outras.

A preocupação de Paulo Freire com a formação do homem para a cidadania no âmbito da escola era recorrente quanto ao domínio de todo o instrumental possível para o despertamento do sujeito cognoscente. Assim, a ação pedagógica do educador se origina numa leitura de mundo, da realidade de sua turma, do conhecimento e das trocas entre os sujeitos cognoscentes. 0 professor, como ator social que também aprende ao ensinar, deve ter sempre em vista que o trabalho com a realidade envolve uma responsabilidade pontual: o planejamento de ações que favoreçam o desenvolvimento de seus alunos num movimento de ressignificação de conhecimentos.

Esse movimento será orientado por um grau de sistematização da intervenção do profissional da educação, mas não de forma inflexível, antes como um objeto que pode desdobrar-se pelas múltiplas interações nas atividades. 0 desdobramento ou a exploração dos elementos que "aparecem evidenciados" em aula não deve ser entendido ou confundido com uma "caixa de improvisações" que prescinde da preparação da aula, da reflexão de possíveis atividades significativas para o grupo, parecendo que o espaço pedagógico se preocupa somente com assuntos especulativos ou subjetividades. Pelo contrário, ele deve ser encaminhado com o objetivo de desenvolver ações que contribuam para que as metas ou finalidades da educação sejam alcançadas. Assim, compreendemos que, ao considerar a leitura do real, temos que pensar em desenvolver as competências e as habilidades dos alunos e em estabelecer as interconexões necessárias para a valorização do ator social e a produção do seu conhecimento. A sensibilização do professor para o aproveitamento, as indagações e as recorrências podem contribuir para uma intervenção pedagógica ressignificada (o desenvolvimento das hipóteses e dos conhecimentos por meio da leitura do contexto real) e intencional (atividades possíveis para o desenvolvimento das atividades mediadas pelo material fornecido pelas interações).

Paulo Freire, o homem, não se distanciava de Paulo Freire, o educador. Antes considerava que educação não poderia ser simplesmente confundida com preparação para a vida, mas deveria envolver a própria vida em processo no aprender e no ensinar a partir da construção do real. Daí a temática central de suas ideias sobre educa- 
ção ser "conscientização", como observaremos na seção seguinte, pois, segundo sua perspectiva: "[...] a educação como prática da liberdade é um ato de conhecimento, uma aproximação crítica da realidade” (Freire, 1980, p. 25).

\section{Paulo Freire: a educação}

A grande contribuição de Paulo Freire centra-se na educação como prática da liberdade, tomando a conscientização como mola propulsora da realidade social, da realidade do ato de ensinar-aprender e intercambiar conhecimentos da vida e para a vida, uma vez que:

A conscientização implica, pois que ultrapassemos a esfera espontânea de apreensão da realidade, para chegarmos a uma esfera crítica na qual a realidade se dá como objeto cognoscível e na qual o homem assume uma posição epistemológica. A conscientização é, nesse sentido, um teste de realidade. Quanto mais conscientização, mais se "des-vela" a realidade, mais se penetra na essência fenomênica do objeto, frente ao qual nos encontramos para analisá-lo. Por esta mesma razão, a conscientização não consiste em "estar frente à realidade" assumindo uma posição falsamente intelectual. A conscientização não pode existir fora da práxis", ou melhor, sem 0 ato ação-reflexão. Esta unidade dialética constitui, de maneira permanente, o modo de ser ou transformar o mundo que caracteriza o homem (Freire, 1980, p. 26, grifos do autor).

A educação formal, para Freire, deve ser sensível ao desdobramento da libertação do indivíduo de uma educação bancária, de uma educação que aliena e oprime perversamente no processo de produção do conhecimento. Observa-se, na orientação da educação bancária, que: a) o professor ensina, os alunos são ensinados; b) o professor sabe tudo, os alunos nada sabem; c) o professor pensa para si e para os estudantes; d) o professor fala e os alunos escutam; e) o professor estabelece a disciplina e os alunos são disciplinados; f) o professor escolhe, impõe sua opção, os alunos submetem-se; g) o professor atua e os alunos têm a ilusão de atuar graças à ação do professor; h) o professor escolhe o conteúdo do programa e os alunos - que não foram consultados - adaptam-se; i) o professor confunde a autoridade do conhecimento com sua própria autoridade profissional, 
que ele opõe à liberdade dos alunos; e j) o professor é sujeito do processo de formação, enquanto os alunos são simples objetos dele.

Freire propõe uma educação problematizadora, balizada pelo respeito, pelo diálogo e pela construção do conhecimento por meio de temas geradores da realidade, explorando-se a criticidade, a criatividade dos alunos, instrumentalizando-os para o exercício da cidadania propriamente dita, pois teriam como reivindicar sua libertação da opressão, do domínio ideológico de interesses sociais particularistas. 0 trabalho pedagógico, proposto por Freire, é revolucionário: não nega o conhecimento historicamente construído, mas enfatiza sua forma de explorá-lo na escola por meio da realidade dos sujeitos. Não enfatiza a indisciplina como ato de educação natural, mas salienta a manifestação do pensamento, como ato libertador dentro de espaços democráticos e éticos.

A esse respeito Paulo Freire afirma que, do ponto de vista ético e democrático, a prática educativa não é neutra em relação à própria formação humana, uma vez que implica opções, rupturas, decisões, posicionamentos. Nessa diretriz, a eticidade do educador e o respectivo exercício democrático exigem-lhe a vigilância permanente da coerência entre o discurso e a ação pedagógica, sendo inócuo um discurso bem articulado, com uma prática negadora do direito à justiça social, a uma educação de qualidade, à emancipação do sujeito. Assim, a

[...] natureza formadora da docência, que não poderia reduzir-se a um puro processo técnico e mecânico de transferir conhecimentos, enfatizar a exigência ético-democrática do respeito ao pensamento, aos gostos, aos receios, aos desejos, à curiosidade dos educandos. Respeito contudo, que não pode eximir o educador, enquanto autoridade de exercer o direito de ter o dever de estabelecer limites, de propor tarefas, de cobrar a execução das mesmas. Limites, sem os quais, as liberdades correm o risco de perder-se em licenciosidade, da mesma forma como sem limites, a autoridade se extravia e vira autoritarismo (Freire, 1997, p. 39).

A educação em Freire, reunindo a necessidade de conscientização, problematização, leitura do real e conteúdos via temas geradores, enfatiza a necessidade de o educador considerar, em seu processo de despertamento, algumas ideias-força que Ihe possibilitarão realizar uma intervenção pedagógica substancialmente transformadora, dentre as quais estão: 
a) Toda ação educativa, para ser válida, deve, necessariamente, ser precedida de uma reflexão sobre o homem e de uma análise do meio de vida concreto de um homem concreto. Freire defendia que não é a ideia sobre o homem que o torna um homem melhor, isto é, uma noção contemplativa de um homem utópico o afasta de qualquer mudança estrutural dele mesmo e de sua história.

b) O homem só constrói a si mesmo pela conscientização de seu papel de ser e estar no mundo. Dentre os desafios que a escola deve enfrentar, podemos destacar: 0 rompimento com o reducionismo tecnocrático no desdobramento da educação formal e a solicitação da visão de conjunto no conhecimento da vida escolar; a interação e a intervenção dos professores, aluno e comunidade, como atores sociais, que reivindicam a sua cidadania, o encampamento da realidade propriamente dita para resolução de conflitos e formulação de orientações que sejam viáveis à vida social e escolar; e a formação de uma consciência coletiva como meio de conscientização da historicidade de seu papel e do seu posicionamento diante de desigualdades e injustiças sociais (Lima, 2013a).

c) O homem é "fazedor" da história. A consciência coletiva aprimora os relacionamentos na consecução de objetivos comuns, pois coloca como ponto de partida a participação de todos os atores sociais envolvidos com a escola e seu entorno. Essa consciência é gerada num espaço democrático, em que os sujeitos se sentem parte indissociável da história e da tomada de decisão sobre o seu destino. Nesse quadro, as solicitações são analisadas em profundidade, e a participação se materializa por meio do exercício do direito de vez, voz e voto. É a partir da consciência coletiva que surgem e são encaminhados os seguintes questionamentos: quem somos? Onde estamos e qual é a finalidade do desenvolvimento do nosso trabalho? Como aperfeiçoar a nossa ação interventiva de forma a promover a melhoria de qualidade do que realizamos? Como nos posicionamos politicamente diante das crises do mundo contemporâneo e, por meio de seus condicionantes, provocamos a crítica-reflexiva? Em que grau e em que medida o trabalho do educador contribui para a formação do indivíduo para o exercício pleno de sua cidadania? As questões norteadoras, emersas de uma consciência coletiva, não se esgotam nessa formulação, mas são indicadoras de que há necessidade real do desenvolvimento de uma outra forma de reivindicar a legitimidade de ação sobre o real, que, embora disponível, muitas vezes não é explorada, por conta do velamento do poder que o coletivo, como fruto da própria formação continuada, pode provocar. 
d) A educação deve contribuir para a constituição do homem como pessoa, como ser histórico, não como ser passivo, simples consumidor. Como afirma Lima (2000), essa educação crítico-reflexiva pode transformar os sujeitos e as condições materiais da existência humana, cujo resultado favorecerá a produção de conhecimentos recorrentes, "lidos" numa perspectiva de mudança, rompimento e ou ratificação de seus pressupostos e, dessa forma, contribui para a formação de uma consciência coletiva no espaço social, do qual a escola é parte indissociável. A ênfase não se dá somente pela importância do trabalho desenvolvido na escola, por meio de uma consciência coletiva - que se caracteriza como prerrogativa nas relações humanas e assume lugar de relevância na construção da totalidade educacional -, mas também pela constatação de que o "si” e o "outro" reconhecem-se humanos e tornam-se atores sociais por meio das trocas e das produções de conhecimento que os humanizam, que os tornam participantes da mesma história, necessariamente articulando o desenvolvimento das contribuições de sua individualidade às construções socializantes que acontecem entre o "si” e o "outro". Não estamos considerando faces isoladas da construção do humano como humano, - a despeito do espaço que estamos tratando: a escola -, mas as interfaces da individualidade que é construída na interação entre sujeitos (a família ou grupos responsáveis) com a socialização, construída pelo encontro de distintos sujeitos que convivem e participam da vida social ativa. Assim, a identidade individual não se perde na coletiva e nem a identidade coletiva marginaliza a individual (Lima, 2013b).

O pensamento educacional de Paulo Freire é leitura contextualizada não somente a partir de literatura especializada, mas de vivências na escola como um todo - educação básica e educação superior -, articulando o embasamento epistemológico e a leitura do real. Nesse sentido, constitui-se uma contribuição para posicionarmo-nos como atores sociais de uma escola que aspira a transformações significativas. Se o nosso compromisso depende de tomar a história como seus produtores, então vale a pena crer que as mudanças são possíveis e podemos verdadeiramente primar por uma educação de qualidade para uma realidade concreta. Lembrando Paulo Freire (1997, p.118, grifos do autor) em sua Política e educação:

Me plenifico na minha missão de educador quando, "brigando" para convencer os educandos do acerto de minha desocultação, me torno transparente eu mesmo ao revelar o meu respeito, primeiro, à recusa possível dos educandos a meu discurso, segundo, o meu respeito à sua antiverdade, com a 
qual recuso a conviver. Me plenifico na minha missão de educador quando revelo, finalmente minha tolerância em face dos diferentes de mim. Ao contrário, desmereço minha missão de educador e a mim mesmo se, em nome do respeito aos educandos, silenciar minhas opções políticas e meus sonhos ou se, em nome de minha autoridade de educador, pretender impor a eles meus critérios de verdade. 0 que me parece fundamental neste respeito às diferenças é o testemunho, por um lado, de que é possível pensar sem prescrições, não só possível, mas sobretudo necessário, e, por outro, que é factível aprender sob o desafio de diferentes formas de ler o mundo. Este respeito sobre que tanto insisto, não pode ser reduzido a uma decisão irresponsável, a um afrouxamento licencioso, a um vale tudo. Daí que eu tenha falado na "briga" legítima do educador ou da educadora em defesa de seu sonho como em defesa da verdade por que se bate ou da utopia que o move ou a move.

É sabido que somente podemos mudar a história da educação que temos pela mobilização de esforços, pelas mudanças de paradigmas, pela coragem do posicionamento no coletivo escolar, pela necessidade da revisitação diária dos nossos saberes e por uma leitura e reorientação sincera, que tenha como objetivo o desenvolvimento de todos os atores sociais e de cada um envolvido no processo da educação na escola, da educação da escola, da educação da vida e para a vida. É exatamente por isso que a intervenção do educador precisa ser consciente e sistematizada, construída num espaço dialogal, que prime pelo respeito às diferenças e às diversidades em todas as suas manifestações, mas, ao mesmo tempo, considere a unidade como âmbito totalizador de multidimensionais leituras.

\section{Paulo Freire: uma janela para o mundo}

De uma janela podemos enxergar somente parte de um mundo complexo, entretanto, a fração apresentada é sempre um convite para o conhecimento pleno do mundo, para a sua provocação, para a sua problematização. Uma janela nos desafia a enxergar e relativizar as parcialidades quando há necessidade do todo, e indo além, as motivações e os interesses que constituem o desvelamento do mundo e do homem. As ideias freireanas certamente como uma janela, como um convite, nos impulsionam para laborar por uma sociedade democrática, humana e universal, por meio de posicionamento, reivindicação por direito e luta por princípio. 
Veja-se, a esse respeito, a visão de mundo que se tinha, nos anos de 1960, sobre a educação escolar, recortando a alfabetização de adultos. Quando se entendia o processo de alfabetização guiado por uma mecânica e uma ação simplesmente instrumentais, Freire o considerava como ato de criação e não de repetição, isto é, conduzido por meio da proposição de temas geradores e ainda, naquela época, utilizando a aprendizagem silábica, delimitava palavras significativas para que a ação sobre o mundo da leitura fosse gerada pelo mundo vivido. Isso porque o seu método era apenas um instrumento de intervenção, uma janela, que favoreceria a conquista de algo maior, centrado na libertação e emancipação do homem. Ao observarmos hoje, seu método constitui-se de uma abordagem simples e de fácil aplicação, como segue:

Primeira fase: descoberta do universo vocabular com o grupo que se há de trabalhar.

Segunda fase: seleção de palavras significativas dentro do universo identificado.

Terceira fase: criação de situações estruturais típicas, a partir do mundo vivido, reflexionando-as no coletivo.

Quarta fase: elaboração de fichas indicadoras que auxiliam os coordenadores no debate a ser trabalhado.

Quinta fase: elaboração de fichas nas quais aparecem as famílias fonéticas correspondentes às palavras geradoras.

Em síntese, partindo do mundo vivido ou do mundo do trabalho em que o indivíduo estava inserido, as palavras ganhavam força, porque refletidas e trazidas para a problematização da situação do trabalhador numa sociedade delimitada por interesse de classes. Essas palavras, tomadas como objeto, separadas em sílabas, por análise e síntese, formação de novas palavras e frases, em si, eram a mecânica da qual lançava mão para favorecer o despertamento do trabalhador, - apenas um instrumento, uma janela que abriria, a posteriori, portas e mobilizaria outros homens e mulheres por uma educação transformadora no Brasil. Freire conseguiu enxergar e erguer a voz a favor das classes oprimidas, dizer o quanto precisávamos entender o sentido do termo “justiça social” e da libertação das desigualdades sociais. A práxis da libertação, no decorrer da obra de Paulo Freire, trouxe-nos à luz a ressignificação ou o sentido, dentre outras, de três palavras: a) opressão: os oprimidos não alcançarão a liberdade por concessão e nem mesmo serão “justiçados” por políticas públicas compensatórias que trazem em si o mascaramento da opressão velada e alienam o homem de se reconhecer como protagonista; b) dependência: se existe a tendência de sua perpetuação, o convite de Freire é por sua superação, pois, ser submisso não 
é não ter uma palavra, mas seguir as determinações daqueles que falam e impõem a sua voz (Lima, 2012) e, o pior de tudo, como eivadas de verdade; c) marginalidade: os excluídos, os oprimidos devem considerar sua situação como sujeitos expropriados, como sujeitos que podem mudar a história em prol de muito mais que de seus direitos, ou seja, de uma sociedade que não trate a opressão de forma naturalizada e torne comum o que é ilegítimo perante o processo civilizatório humano.

Como observado por Lima (2013a) essa é uma das interfaces do posicionamento político que o educador assume. Político porque possibilita a emancipação de si como pessoa, como cidadão que forma outros cidadãos e como profissional que reúne o compromisso de aperfeiçoar-se, de aprimorar-se por conta do desenvolvimento de habilidades e competências dos outros (alunos e professores e outros atores sociais). É um ato político porque transforma e se transforma em diálogo na busca de reivindicações legítimas de melhoramentos pessoais e coletivos dentro do universo cultural, social, econômico, político, etc.

Por meio da janela proposta por Freire, percebemos que o ato de educar deve prescindir da autossuficiência, pois o reconhecimento do outro e de si são dimensões indispensáveis das necessárias intervenções sobre os interesses históricos daqueles que lutam por justiça. Nenhum dos movimentos, entretanto, se dá isoladamente e sem porquês. Se considerarmos a totalidade do equilíbrio universal, o mesmo ocorre quando do reconhecimento de "si" no âmbito social. Importa que o homem se reconheça como ser humano, como cidadão, como pessoa e como profissional da educação. Todos esses reconhecimentos, no âmbito da formação da individualidade, também não se dão isoladamente, embora o ator social apresente particularidades que são só suas. As interações pelas quais passou ao longo de sua vivência contribuíram para o desenvolvimento de sua personalidade, de sua individualidade. Mas, ao mesmo tempo em que exerce sua individualidade, o "si" deve buscar no reconhecimento do outro, de sua importância e papel na ação comunicacional a afirmação da busca de propósitos, o compartilhamento das contribuições geradas a partir de sua individualidade e o desenvolvimento do "eu" e do "nós" na recorrente trajetória histórica. A esse respeito, vale lembrar que:

A autossuficiência é incompatível com o diálogo. 0s homens que não têm humildade ou a perdem, não podem aproximar-se do povo. Não podem ser seus companheiros de pronúncia do mundo. Se alguém não é capaz de sen- 
tir-se e saber-se tão homem quanto os outros, é que lhe falta ainda muito que caminhar, para chegar ao lugar de encontro com eles. Neste lugar de encontro, não há ignorantes absolutos, nem sábios absolutos: há homens que em comunhão buscam saber mais (Freire, 1987, p. 46, grifo do autor).

Essa concepção do homem como ser político-social adquire, como lembra Lima (2008, p. 467), um caráter libertador, pois é um ato de conhecimento, uma apropriação legítima da realidade que considera “a vocação ontológica do homem - vocação de ser sujeito - e as condições em que ele vive: em tal lugar exato, em tal momento, em tal contexto" (Freire, 1980, p. 34). Nesse sentido, a educação não pode ser dissociada de um posicionamento político pelo professor, que, como sujeito recorrente, apropria-se dos fundamentos epistemológicos, articula-os de forma reflexiva à realidade, sem fragmentações, e cresce, de forma solidária e cidadã, junto com o sujeito cognoscente.

A integração de múltiplas vozes constitui a dimensão de totalidade das aprendizagens do homem, quer na escola da vida, quer na vida da escola ou no afrontamento de realidades promotoras de desigualdades e injustiças sociais. Esse processo, não sendo linear, exige dos homens o viver junto em ressignificação de valores, isto é, por meio do estabelecimento do que é importante e/ou prioritário para o grupo humano ou sociedade, vão sendo eleitos os pressupostos que orientarão a prática social, bem como a noção de ética e moralidade entre os sujeitos. Acerca dessa observação, vale destacar que os valores convencionados entre os homens surgem de suas trocas - entre o si e o outro - como expressão da leitura coletiva e em respeito a ela (Lima, 2008).

Em relação ao papel do professor, por meio do olhar freireano, podemos inferir que a tomada de consciência para uma prática pedagógica ressignificada na e pela convivência é um exercício de aprendizagem que aprimora o reconhecimento de que os conhecimentos, os valores, os sentidos das ações docentes são construídos por múltiplas vozes que solicitam encontros dialéticos permanentes, que, em si, estão sempre em estado de "novidade de encaminhamentos e propósitos", não pelo ineditismo de temáticas da escola e seu entorno, mas pelo acuramento do olhar sobre os fundamentos, as consequências e as implicações que tais objetos demandam diante de interesses identificados que inquietam os interlocutores por seu ocultamento. Dessa maneira, a prática pedagógica, ressignificada na convivência, possibilita uma outra forma de aprendizagem para os alunos, para o professor e para toda a comuni- 
dade escolar. O espaço de convivência não é o espaço onde os conflitos não existem, muito pelo contrário, é também o espaço onde se possibilita a exposição dos conflitos. Longe de se constituir um muro de lamentações, caracteriza-se como uma "ponte" onde ninguém poderá atravessar no lugar dos interlocutores, porque a travessia, sendo personalizada, é um caminho de todos. Assim as resoluções dos conflitos são encaminhadas, pensadas e discutidas a partir da evocação das inquietações dos sujeitos. Sabe-se que as respostas podem até não ser consensuais, respeitada a diversidade das individualidades, mas podem alcançar uma dimensão democrática significativa em relação à unidade (uno) dos objetivos que todos compartilham, mesmo que de ponto de vista diferenciado. Mudam os sujeitos, consequentemente, a prática pedagógica será orientada por uma autoridade legitimada em múltiplas leituras, em que todos, ao mesmo tempo, são atores e protagonistas da vida real da escola.

Orientados pelo pensamento freireano, considerando a sua janela para o mundo, Lima (2009) pondera que o conhecimento da vida escolar, de suas relações, indagações, êxitos, fracassos, completudes e incompletudes em relação às políticas públicas para a educação; em relação à dimensão das relações interpessoais; em relação à organização, metas e projetos da escola, solicita uma visão de conjunto para que seus contextos e condicionantes sejam suficientemente entendidos e problematizados. Dessa maneira, a educação, em sua finalidade primordial, poderá encontrar encaminhamentos significativos como indicadores de seu norteamento. $\mathrm{Na}$ sociedade do conhecimento em que vivemos, que se caracteriza pelo processo ensino-aprendizagem permanente e continuado (mundo globalizado e em processo de globalização), se houver comprometimento democrático e justiça social em sua dimensão plena, não é possível entender a escola e suas relações, cujo dever formal se completa na formação de sujeitos determinados para uma sociedade impessoalizada e alienante, como se estivessem desvinculadas da totalidade social, materializando seus esforços simplesmente como transmissora de conhecimentos.

A visão de conjunto toma a totalidade como fio condutor, a fim de acompanhar todo um processo que se torna revolucionário no afrontamento ao reducionismo e à fragmentação, que ruma à proposição de delineamentos coerentes e consistentes com o real social e educacional, revisão essa que não mais admite padronizações dos próprios saberes e fazeres da escola, nem de verdades e visão de homem determinadas pela manutenção de vontades particularistas. Daí a importância de uma educação compreensiva, balizada em valores sociais, antropológicos, políticos, filo- 
sóficos, culturais e, sobretudo, valores humanos universalizados. Esse norteamento é o veículo que vai situar a escola como elemento de transformação social; assim, importa que o professor, em seu processo de formação continuada, conheça, inclua em seu comprometimento pela educação a totalidade da leitura, contexto pelo qual atravessa o mundo, o planeta, o País, o estado, o município, o bairro, a comunidade extraescolar e a escola como objeto indissociáveis do conhecimento. Esse primeiro momento pressupõe o conhecimento das reais condições e possibilidades da escola e, convertendo-se em vetores significativos, apontam a escola que temos e fornecem elementos para a planificação da escola que esses queremos.

\section{Considerações finais}

A leitura do mundo antecede a leitura da palavra, e importa que, uma vez feita a primeira, a segunda dê ressignificação ao seu conteúdo, ao seu texto e contexto, evocando da memória aqueles elementos imprescindíveis que tornam o homem um sujeito construtor de sua própria história. É na articulação dessas leituras que o professor deve se orientar para o desenvolvimento da intervenção pedagógica, não numa leitura linearizada, como se todas as leituras das situações e dos registros fossem predeterminadas e prontamente direcionadas a tomadas de decisão.

A leitura do mundo caracteriza-se pelo conhecimento das relações estabelecidas pelos homens na sua construção de sociedade, portanto, do seu mundo concreto e do imaginário que o cerca: seus valores, visões, expectativas, etc. Por outro lado, a leitura da palavra sobre o mundo caracteriza-se pelos registros realizados da/na história e a partir de que olhar o são. Nesse entrecruzamento está o homem, aqui personificado no papel do professor, que precisa realizar uma leitura ressignificada do mundo e da palavra, o que exige dele um posicionamento dialético e político. 0 posicionamento dialético permite-lhe "ler" o mundo de uma maneira não linearizada, isto é, analisa os “ditos" e os "contra-ditos” da história do homem e da educação; assim, à medida que conhece a realidade, identifica os elementos necessários para a contestação de posturas e a ratificação de explicações do mundo e do homem em seu processo de constituição. No âmbito político, os posicionamentos são analisados, tendo em vista a finalidade social do objeto de estudo: se está sendo alcançada ou não; se há a reivindicação dos direitos simultaneamente aos deveres do cidadão; se, no processo da vida social e escolar, há ou não ênfase para o desenvolvimento de espaços democráticos. Ambos, político e dialético, são interfaces de uma sensibilização 
de uma leitura de mundo e da palavra que devem ser efetuadas, tendo em vista os desafios - que não são poucos - da escola contemporânea. Tais desafios perpassam o interesse de toda a sociedade, e a escola, como instituição educadora, não pode ficar alheia.

Paulo Freire foi um dos mais importantes representantes da educação popular do século XX. Para ele, um dos pontos importantes da educação popular é a percepção de que não existe ninguém mais culto que o outro. Não acredita numa pedagogia, nem em nenhuma transformação revolucionária feita para as massas populares, mas, sim, com elas e por meio delas. Diz que é necessária uma postura humilde do educador para o exercício consciente de sua ação interventiva no processo pedagógico, mas não humildade de fazer favor, de pura tática, uma vez que é fundamental respeitar o princípio de que a dimensão educativa é um processo coletivo, no qual o educador tem que se apropriar dos mecanismos pedagógicos de expressão e explicitação das lutas, das dúvidas, das incertezas, com senso crítico para a problematização e a transformação da realidade. 


\section{Referências bibliográficas}

FREIRE, Paulo. Conscientização, teoria e prática da libertação: uma introdução ao pensamento de Paulo Freire. São Paulo: Moraes, 1980.

FREIRE, Paulo. Pedagogia do oprimido. 17. ed. Rio de Janeiro: Paz e Terra, 1987.

FREIRE, Paulo. Política e educação. São Paulo: Cortez, 1997.

LIMA, Paulo Gomes. Educação escolar e formação continuada de professores: para aprender a viver juntos. In: SEMINÁRIO DE ESTÁGIO SUPERVISIONADO: DIÁLOGOS ENTRE LICENCIATURAS DA UFGD, 1. e FÓRUM DE LICENCIATURAS UEMS, 2., 30 set./2 out. 2009, Dourados-MS. Comunicação oral.

LIMA, Paulo Gomes. Fundamentos teóricos e práticas pedagógicas. Engenheiro Coelho/SP: Centro Universitário Adventista de São Paulo, $2013 a$.

LIMA, Paulo Gomes. La formación del educador reflexivo: notas para la orientación de su práctica. Revista Latinoamericana de Estudios Educativos, México, v. XXX, n. 3, p. 117-127, 2000.

LIMA, Paulo Gomes. Saberes pedagógicos da educação contemporânea. Engenheiro Coelho, SP: UNASP, 2013b.

LIMA, Paulo Gomes. Transversalidade e docência universitária: por uma recorrência dialética do ensinar e aprender. Educação, Santa Maria, v. 33, n. 3, p. 457-468, set./ dez. 2008.

LIMA, Paulo Gomes. Universidade e educação básica no Brasil: a atualidade do pensamento de Paulo Freire. Dourados: Editora da UFGD, 2012.

Submetido à avaliação em 13 de julho de 2013.

Aprovado para publicação em 28 de agosto de 2014. 